\title{
Prosthodontic Management of a Pediatric Patient with Christ-Siemens-Touraine Syndrome: A Case Report
}

Anshad M Abdulla ${ }^{1}$, Abdulrahman Y Almaliki ${ }^{2}$, Nasim V Shakeela ${ }^{3}$, Zuhair Alkahtani ${ }^{4}$, Majed AS Alqahtani ${ }^{5}$, Shan Sainudeen $^{6}$, Shaheen V Shamsuddin ${ }^{7}$

\begin{abstract}
Ectodermal dysplasias (ED) are a group of rare genetic disorders characterized by congenital defects involving two or more ectodermal structures. Christ-Siemens-Touraine syndrome or hypohidrotic ectodermal dysplasia is the commonest form of ED. Hypohidrotic ectodermal dysplasia (HED) is an X-linked disorder characterized by excessively dry skin due to the absence of sweat glands (anhidrosis), sparse body hair especially on the scalp and eyebrows (hypotrichosis), brittle nails, absence of sebaceous glands (asteatosis) and malformed or absent teeth. Oral manifestations include oligodontia or complete anodontia, conical teeth, underdeveloped alveolar ridges, generalized spacing and delayed eruption of permanent teeth. This case report discusses a classical case of HED and the options for rehabilitation in a growing patient. A thorough knowledge about the clinical manifestations of ED will lead to proper diagnosis and appropriate treatment plan thereby leading to significant improvements in esthetics, phonetics and masticatory function in ED patients, which in turn leads to improved quality of life in these individuals.
\end{abstract} Keywords: Christ-Siemens-Touraine Syndrome, Ectodermal dysplasia, Prosthodontic management.

International Journal of Clinical Pediatric Dentistry (2019): 10.5005/jp-journals-10005-1697

\section{INTRODUCTION}

Ectodermal dysplasias (EDs) are a group of rare genetic disorders characterized by congenital defects involving two or more ectodermal structures. ${ }^{1}$ It was first described by Thurnam in 1848 and has an estimated incidence of 1 in 1,00,000 births. ${ }^{2,3}$ In 1921, EDs were linked to $X$ chromosomes by Thadani. ${ }^{3}$

Ectodermal dysplasias are mainly of two types based on the function of sweat glands and its number namely Clouston syndrome or hidrotic ED and Christ-Siemens-Touraine syndrome or hypohidrotic ectodermal dysplasia (HED). ${ }^{4}$ Among the two types, the HED is the commonest. HED is an X-linked disorder characterized by excessively dry skin due to the absence of sweat glands (anhidrosis), sparse body hair especially on the scalp and eyebrows (hypotrichosis), brittle nails, absence of sebaceous glands (asteatosis), and malformed or absent teeth. ${ }^{5,6}$

Along with these features, the affected individuals might show other manifestations like heat intolerance, prominent supraorbital ridges, protuberant lips, and depressed nasal bridge. Oral manifestations include oligodontia or complete anodontia, conical teeth, underdeveloped alveolar ridges, generalized spacing, and delayed eruption of permanent teeth. ${ }^{6,7}$

In pediatric patients with HED, restoration of oral esthetics is vital, if not it can affect their psychological well-being. A complete oral rehabilitation of these patients is of paramount importance from a functional, physiologic, and psychosocial point of view., ${ }^{8,9}$ There are various treatment modalities for managing oligodontia or anodontia in pediatric HED patients, but the most frequently preferred is removable prosthodontics. ${ }^{10}$ Since these patients have underdeveloped alveolar ridges due to the lack of teeth, construction of dentures is more challenging than usual. This report describes an oral rehabilitation of a pediatric patient with Christ-Siemens-Touraine syndrome.

\section{Case Description}

A 7-year-old boy presented with the chief complaint of missing teeth, difficulty in mastication, difficulty in speech, and lack of
1,3,4,7 Department of Pediatric Dentistry and Orthodontic Sciences, King Khalid University, Abha, Kingdom of Saudi Arabia

2,5 Department of Dentistry, King Khalid University, Abha, Kingdom of Saudi Arabia

${ }^{6}$ Department of Restorative Dentistry, King Khalid University, Abha, Kingdom of Saudi Arabia

Corresponding Author: Anshad M Abdulla, Department of Pediatric Dentistry and Orthodontic Sciences, King Khalid University, Abha, Kingdom of Saudi Arabia, Phone: +966 537820023, e-mail: anshad@ kku.edu.sa

How to cite this article: Abdulla AM, Almaliki AY, Shakeela NV, et al. Prosthodontic Management of a Pediatric Patient with ChristSiemens-Touraine Syndrome: A Case Report. Int J Clin Pediatr Dent 2019;12(6):569-572.

Source of support: Nil

Conflict of interest: None

esthetics. On general examination, he had scanty eyebrows and eyelashes, dry and wrinkled skin, depressed nasal bridge, prominent supraorbital ridge, everted dry lips, and hyperpigmentation around the eyes (Fig. 1). Hair over the scalp were sparsely distributed (Fig. 2). Finger nails were brittle (Fig. 3). On oral examination, there was delayed eruption of permanent dentition, conical maxillary anterior teeth, and partial anodontia (Fig. 4). Bone ridge on the mandibular anterior region was very thin (Fig. 5). Panoramic radiograph showed evidence of tooth formation in both the jaws, and six tooth buds were present probably related to maxillary incisors and second permanent molars. All the second primary molars and first permanent molars were present. Four cone-shaped crowns suggestive of primary canines were also seen (Fig. 6).

During the physical examination, the patient showed no signs of mental problems and his vital signs were normal. His father said that his child was not able to sweat. He also stated that there was no production of tears when his child cried. Nobody in the 


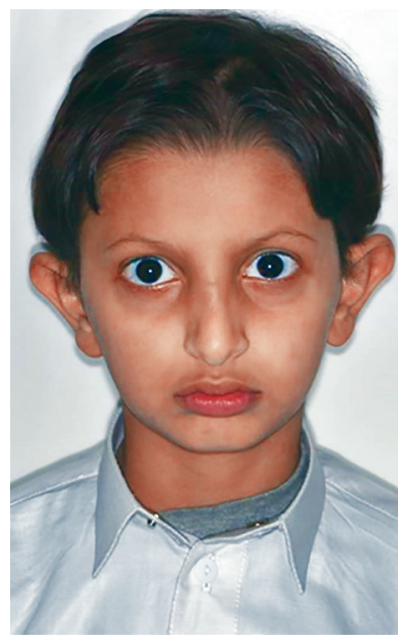

Fig. 1: General examination of the patient reveals scanty eyebrows and eyelashes with wrinkled hyperpigmented skin around the eyes

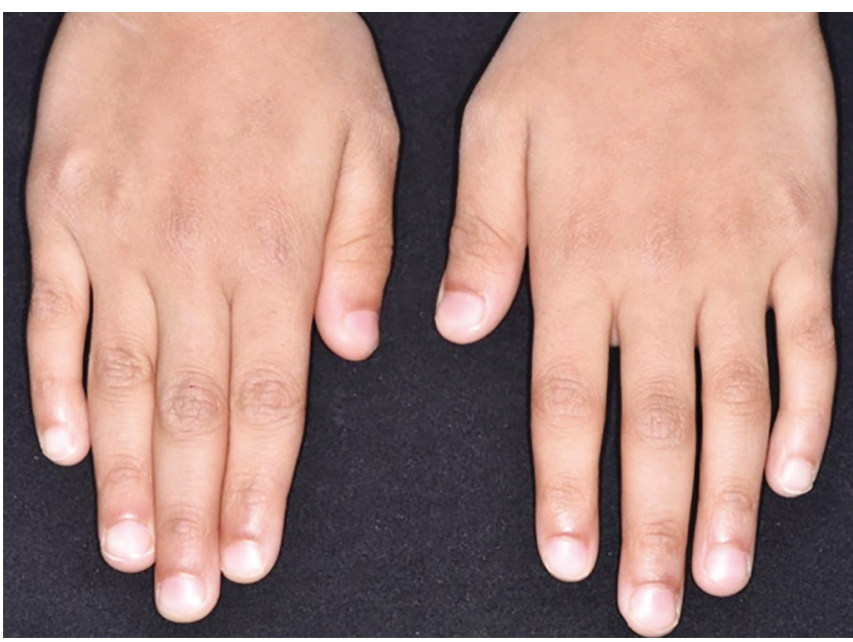

Fig. 3: Brittle finger nails

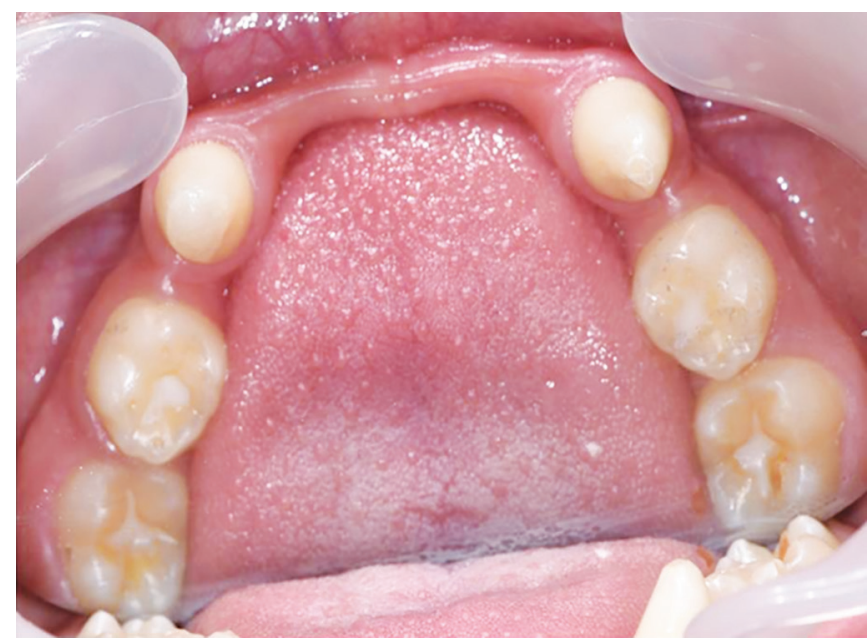

Fig. 5: "Knife-edge" morphology of mandibular ridge in anterior region

patient's family had similar condition and he was born of nonconsanguineous marriage.

A sweat pore count test was done in which starch-iodine powder was applied to the dorsal skin. In this patient due to the

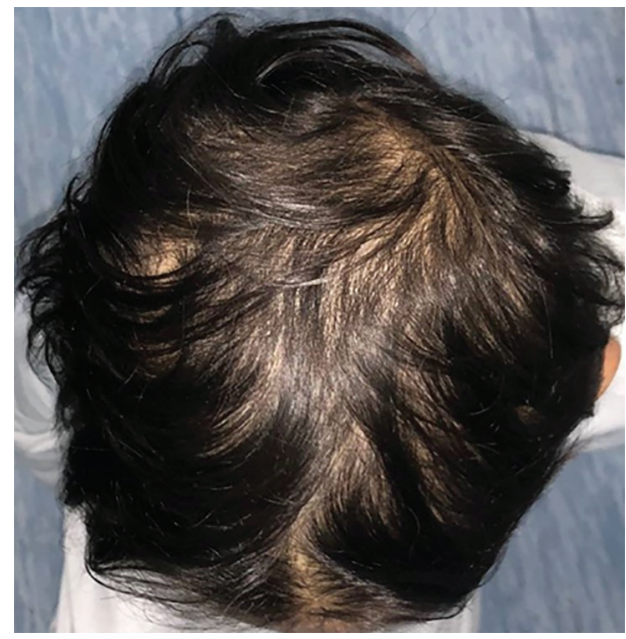

Fig. 2: Sparsely distributed scalp hair

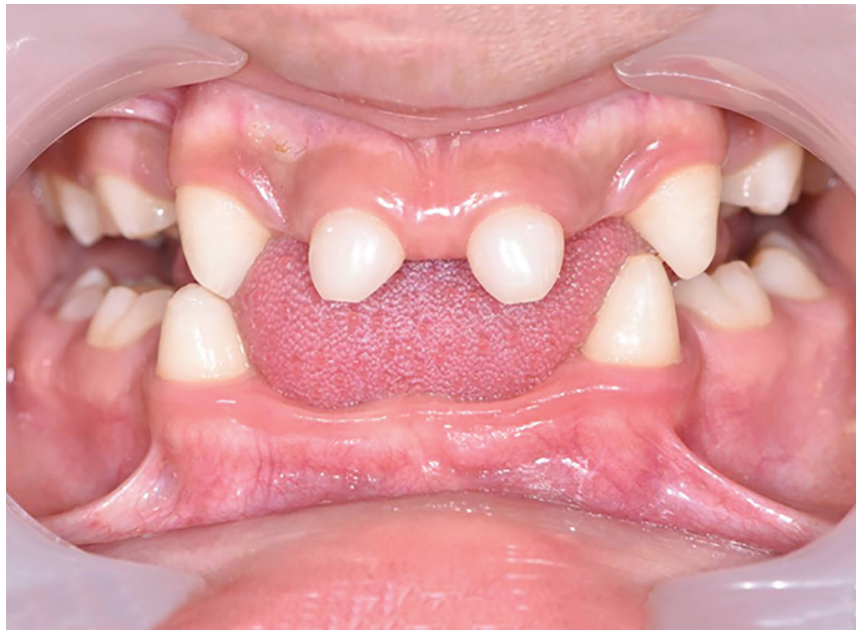

Fig. 4: On oral examination, there was delayed eruption of permanent dentition, conical maxillary anterior teeth, and partial anodontia

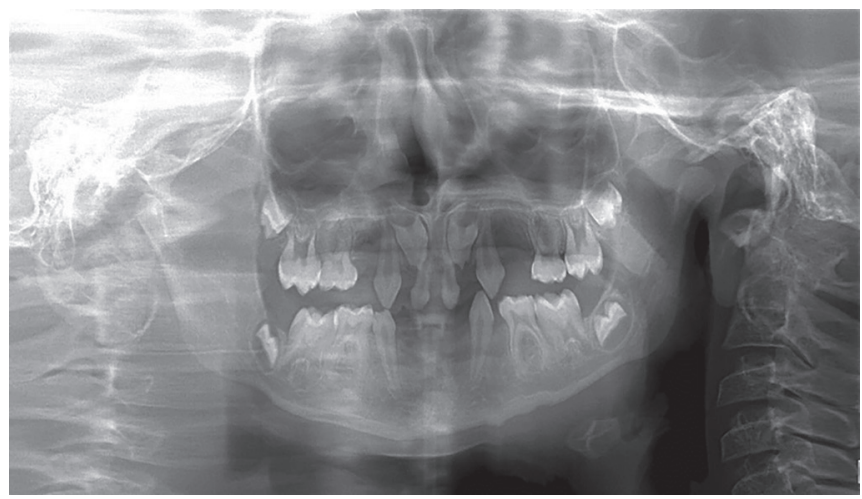

Fig. 6: Panoramic radiograph shows the eruption of all the first permanent molars and 10 teeth of primary dentition. Six tooth buds probably related to maxillary incisors and second permanent molars are also seen

lack of sweat, starch-iodine powder did not change color to deep purple and sweat pores were poorly visible.

Based on the case history, clinical examination, and investigations, a diagnosis of Christ-Siemens-Touraine syndrome 


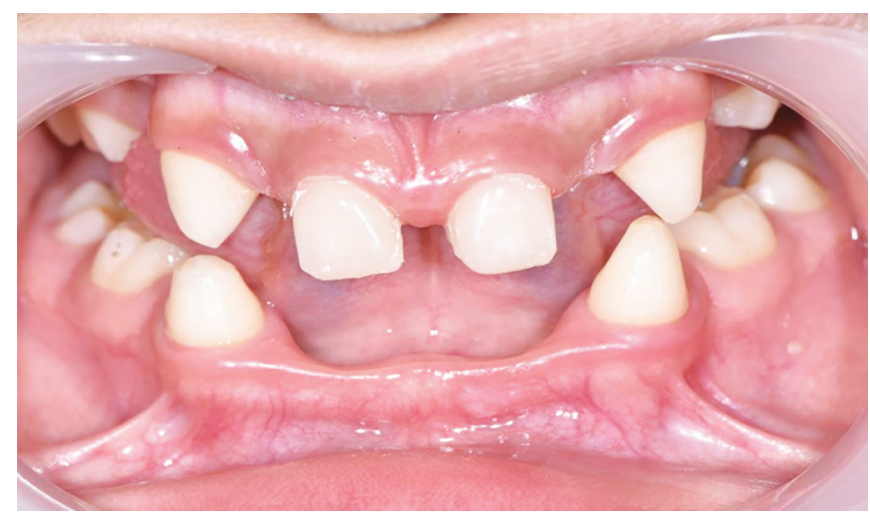

Fig. 7: Composite buildup of the conical maxillary anterior teeth was done using strip crowns

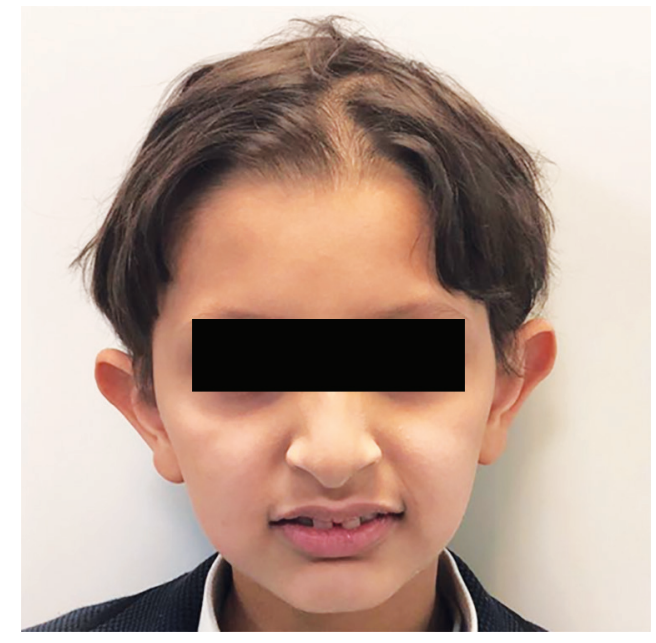

Fig. 9: Postinsertion extraoral view

or HED was made. Removable partial dentures were considered as the treatment option for this patient. Prior to impression making, composite buildup of the conical maxillary anterior teeth was done using strip crowns (Fig. 7). Primary impressions were made with alginate, and then custom trays were fabricated for functional impression. Acrylic bases with occlusal wax rims were made on the master casts for establishing maxillomandibular relations. Primary tooth forms were selected for better esthetics, maintenance of physiologic spaces, and to provide static occlusion. After the final insertion (Figs 8 and 9), routine oral hygiene instructions for the dentures like maintaining a soft diet for few days and to remove the dentures at night for promoting the healing of the oral soft tissue, etc., were given to both the child and his father. Periodic follow-up was advised for modification or replacement of the dentures taking into consideration the patient's developing maxillary and mandibular ridge.

\section{Discussion}

Christ-Siemens-Touraine syndrome or HED is the most frequently seen type of ED. It is said to occur due to any genetic defect in ectodysplasin signal transduction pathways. ${ }^{6}$ During morphogenesis, epithelial cells in developing teeth, hair follicles, nails, and sweat glands make use of this pathway and any genetic defect can lead to dysplasia, hypoplasia, or aplasia of these

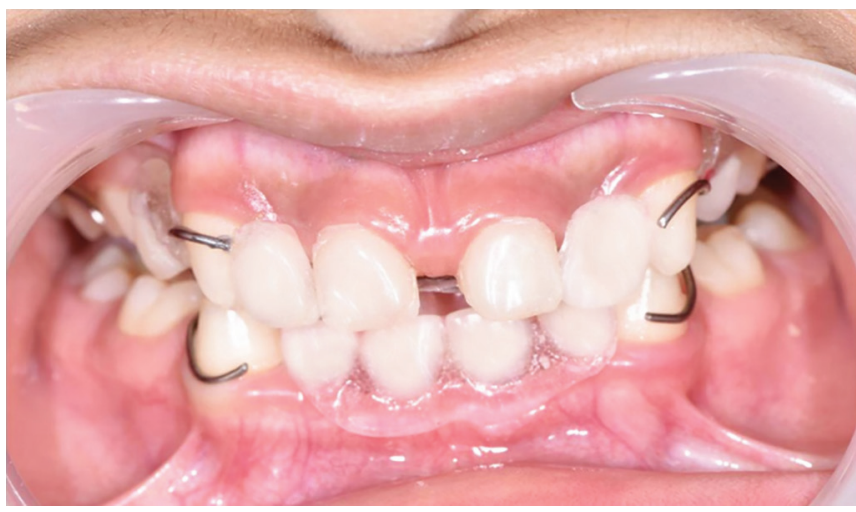

Fig. 8: Postinsertion intraoral view

structures. Oral manifestations of these disturbances include hypodontia, tooth malformations, and hypoplasia of teeth. ${ }^{11,12}$ In the present case, the patient showed typical features of ChristSiemens-Touraine syndrome in his face and oral cavity.

Prosthodontic rehabilitation at an early age in such cases has various advantages. It helps the child to adjust with the prosthesis and develop normal appearance. The phonetics, mastication, and the temporomandibular joint function are also developed. Removable partial dentures were considered as the best treatment option for this patient considering the patient's age, need for mastication, phonetics, esthetics, and overall psychological well-being. During growth spurts, the prosthesis can be modified based on the developing alveolar ridges. ${ }^{13}$ Apart from oral benefits, an early prosthodontic intervention also imparts psychological benefits. ${ }^{14}$ But sometimes a "knife-edge" morphology as seen with the mandibular ridge in this case along with decreased alveolar bone height make oral rehabilitation an arduous task in such patients.

Prosthodontic rehabilitation of a patient with HED can include fixed, removable, or implant supported prosthesis. Fixed partial dentures are not commonly used in the treatment of HED because of the limited number of teeth (hypodontia) to act as abutments. There also a possibility of fixed prosthesis interfering with jaw growth in growing patients due to rigid connectors if the prosthesis crosses the midline. ${ }^{15}$

Oral rehabilitation by dental implants is usually limited to patients who have completed craniofacial growth and is best advised to delay until adolescence. Implants placed in growing patients can cause several problems like the implant prosthesis being submerged and acting like an ankylosed tooth, restrictions on skeletal craniofacial growth and trauma to tooth buds. According to Yap and Klineberg, implants placed in ED patients before the age of 18 years have a higher risk of failure. ${ }^{16}$

In the present case, dental implant therapy was not an option due to incomplete craniofacial growth and lack of alveolar bone support.

Therefore, in child patients and adolescents with HED, removable partial dentures provide the most logical reversible treatment option that enhances esthetics and function without threatening an already compromised dentition. ${ }^{13}$

\section{Conclusion}

The prosthetic rehabilitation of ED cases is often very challenging, particularly in pediatric patients and therefore a 
multidisciplinary treatment plan involving pediatric dentist, orthodontist, prosthodontist, and an oral-maxillofacial surgeon is absolutely vital for complete restoration of oral function. In the present case, since the patient is a growing child, periodical reviewing for the modification of the transitional removable appliance is required to compensate for the continued growth and development. Once the skeletal growth is complete, the patient can opt for a definitive prosthesis like implant supported dentures.

Dental practitioners are often among the first to identify these patients due to characteristic oral and extraoral features. Therefore, a thorough knowledge about the clinical manifestations of this condition will lead to proper diagnosis and appropriate treatment plan, thereby leading to significant improvements in esthetics, phonetics, and masticatory function in ED patients, which in turn leads to improved quality of life in these individuals.

\section{References}

1. Kothiwala SK, Prajapat M, Kuldeep CM. Christ-Siemens-Touraine syndrome with palmoplantar keratoderma: a rare association. Indian Dermatol Online J 2016;7(5):393-395. DOI: 10.4103/2229-5178. 190506.

2. Thurnam J. Two cases in which the skin, hair and teeth were very imperfectly developed. Proc R Med Chir Soc 1848;31:71-82. DOl: $10.1177 / 095952874803100108$.

3. Ladda R, Gangadhar S, Kasat V, et al. Prosthodontic management of hypohidrotic ectodermal dysplasia with anodontia: a case report in pediatric patient and review of literature. Ann Med Health Sci Res 2013;3(2):277-281. DOI: 10.4103/2141-9248.113679.

4. Lesot $\mathrm{H}$, Clauss $\mathrm{F}$, Manière $\mathrm{MC}$, et al. Consequences of $\mathrm{X}$-linked hypohidrotic ectodermal dysplasia for the human jaw bone. Front Oral Biol 2009;13:93-99. DOI: 10.1159/000242398.
5. Coelho LG Jr, Caldas AF Jr, Soriano EP, et al. Christ siemens touraine syndrome: a case report. Cases J 2009;2(1):38. DOI: 10.1186/17571626-2-38.

6. Mokhtari S, Mokhtari S, Lotfi A. Christ-Siemens-Touraine syndrome: a case report and review of the literature. Case Rep Dent 2012; 586418. DOI: $10.1155 / 2012 / 586418$.

7. Retnakumari N, Varghese M, Kannan VP. Christ siemens touraine syndrome: a rare case report. J Indian Soc Pedod Prev Dent 2016;34(2):185-188. DOI: 10.4103/0970-4388.180451.

8. Gupta S, Tyagi P. Prosthodontic management of anhidrotic ectodermal dysplasia. Indian J Dent Res 2011;22(2):348-351. DOI: 10.4103/0970-9290.84291.

9. Shigli A, Airen SP. Prosthodontic management of patients with ChristSiemens-Touraine syndrome. BMJ Case Rep 2012;2012:bcr1120115226. DOI: 10.1136/bcr.11.2011.5226.

10. Bidra AS, Martin JW, Feldman E. Complete denture prosthodontics in children with ectodermal dysplasia: review of principles and techniques. Compend Contin Educ Dent 2010;31(6):426-433.

11. Balci G, Baskan SZ, Akdenizi S. Ectodermal dysplasia: report of four cases and review of literature. Int Dent Med Disord 2008;1:56-59.

12. Lexner MO, Bardow A, Hertz JM, et al. Anomalies of tooth formation in hypohidrotic ectodermal dysplasia. Int J Paediatr Dent 2007;17(1): 10-18. DOI: 10.1111/j.1365-263X.2006.00801.x.

13. Jain N, Naitam D, Wadkar A, et al. Prosthodontic rehabilitation of hereditary ectodermal dysplasia in an 11-year-old patient with flexible denture: a case report. Case Rep Dent 2012;2012:489769. DOI: 10.1155/2012/489769.

14. Hickey AJ, Vergo TJ. Prosthetic treatments for patients with ectodermal dysplasia. J Prosthet Dent 2001;86(4):364-368. DOI: 10.1067/mpr.2001.118876.

15. Pigno MA, Blackman RB, Cronin RJ, et al. Prosthodontic management of ectodermal dysplasia: a review of the literature. J Prosthet Dent 1996;76:541-545. DOI: 10.1016/S0022-3913(96)90015-3.

16. Yap AK, Klineberg I. Dental implants in patients with ectodermal dysplasia and tooth agenesis: a critical review of the literature. Int J Prosthodont 2009;22(3):268-276. 